\title{
Diurnal IOP-lowering efficacy and safety of travoprost $0.004 \%$ compared with tafluprost $0.0015 \%$ in patients with primary open-angle glaucoma or ocular hypertension
}

\author{
This article was published in the following Dove Press journal: \\ Clinical Ophthalmology \\ 7 December 2010 \\ Number of times this article has been viewed
}

\author{
Dietmar Schnober' \\ Günter Hofmann² \\ Hubert Maier ${ }^{3}$ \\ Maria-Luise Scherzer ${ }^{4}$ \\ Abayomi B Ogundele ${ }^{5}$ \\ Mark C Jasek ${ }^{5}$ \\ 'Private Practices, Werdohl, \\ ${ }^{2}$ Schweinfurt, ${ }^{3}$ Gerolzhofen, \\ ${ }^{4}$ Regenstauf, Germany; ${ }^{5}$ Alcon \\ Laboratories Inc, Fort Worth, \\ TX, USA
}

Correspondence: Dietmar Schnober Friedrich-Keßler-Platz 5, 5879l

Werdohl, Germany

$\mathrm{Tel}+239210001$

Fax +23 92I 4455

Email dr.schnober@t-online.de
Purpose: To compare the diurnal intraocular pressure (IOP)-lowering efficacy and safety of travoprost $0.004 \%$ and tafluprost $0.0015 \%$ administered to patients with primary open-angle glaucoma or ocular hypertension.

Methods: This was a randomized, double-masked, active-controlled, crossover design trial, in which patients were randomized to either travoprost or tafluprost monotherapy administered once daily in the evening for six weeks and then crossed over to the alternative treatment for another six weeks. Diurnal IOP was measured ( 8 am to $8 \mathrm{pm}$, every two hours) and a solicited symptom survey was administered at the end of both six-week periods, as was conjunctival hyperemia and visual acuity assessment, slit-lamp biomicroscopy, and adverse event solicitation.

Results: Fifty-one patients were randomized and 48 patients completed the study. The 12-hour mean diurnal IOP was significantly lower with travoprost therapy than with tafluprost therapy $(P=0.01)$, and a significantly lower IOP was also reported for travoprost at five of the seven individual time points $(P<0.05)$. Neither therapy produced a significant increase from baseline in any of the individual patient-reported symptom scores, except for hyperemia $(P \leq 0.01)$, which was increased with both treatments. Investigator-observed hyperemia was also increased from baseline with both therapies $(P<0.01)$, although the increase with travoprost therapy was significantly smaller than with tafluprost $(P<0.01)$. No additional safety concerns were noted from slit-lamp biomicroscopy or visual acuity results, and no difference was noted in patient-reported tolerability of the two medications.

Conclusion: Travoprost $0.004 \%$ monotherapy produced lower diurnal IOP than tafluprost $0.0015 \%$ in patients with primary open-angle glaucoma or ocular hypertension and exhibited a similar safety profile.

Keywords: glaucoma, intraocular pressure, prostaglandin analog, tafluprost, travoprost

\section{Introduction}

Elevated intraocular pressure (IOP) is considered a key risk factor for the progression of glaucoma. ${ }^{1,2}$ As such, IOP reduction is a primary objective of the pharmacologic treatment of glaucoma. ${ }^{3}$ Several studies have demonstrated that IOP reduction does, in fact, slow glaucoma progression. ${ }^{4-6}$

Prostaglandin analogs are among the most potent IOP-lowering therapies currently available. $^{3}$ These include latanoprost, travoprost, tafluprost, and bimatoprost. Prostaglandin analogs have demonstrated greater IOP-lowering efficacy than beta-adrenergic blockers ${ }^{7}$ and, for that reason, are commonly used as first-line therapy against glaucoma. ${ }^{3}$ In addition, all prostaglandin analogs have convenient once-daily dosing, whereas some other 
IOP-lowering therapies require dosing two to three times daily. In 1996, latanoprost $0.005 \%$ (Xalatan ${ }^{\circledR}$; Pfizer, New York, NY) was the first prostaglandin analog to be approved by the US Food and Drug Administration for the treatment of ocular hypertension and open-angle glaucoma. Travoprost $0.004 \%$ (Travatan $^{\circledR}$; Alcon Laboratories Inc, Fort Worth, TX), another prostaglandin analog, was approved in 2001 for a similar indication. ${ }^{8}$ Tafluprost $0.0015 \%$ (Taflotan $^{\circledR}$; Santen Oy, Tampere, Finland) is the most recently released prostaglandin analog, being approved in Europe in 2008 but not yet approved in the US.

It is well established that IOP is subject to circadian variation in both healthy individuals and those with glaucoma, although IOP fluctuation is magnified in glaucomatous eyes. ${ }^{9}$ Thus, effective once-daily IOP-lowering medications must have consistent efficacy throughout the day to reduce the risk of IOP spikes, which have been associated with the progression of glaucoma. ${ }^{10}$ Travoprost $0.004 \%$ has not only demonstrated significant reductions in IOP throughout a 24-hour period but also it has shown superior late afternoon (4 pm and $6 \mathrm{pm}$ ) efficacy compared with that of latanoprost $0.005 \% .^{11,12}$ Data from a Phase III trial suggest that tafluprost $0.0015 \%$ may have efficacy similar to that of latanoprost. ${ }^{13}$ Thus, because of the apparent superiority of IOP control by travoprost over latanoprost in the late afternoon, it is reasonable to speculate that travoprost and tafluprost may show a pattern of IOP-lowering efficacy that is similar to that of travoprost and latanoprost. However, due to the recent addition of tafluprost to the marketplace, limited clinical information currently exists directly comparing tafluprost with other prostaglandin analogs. The aim of the current study was to compare the diurnal IOP-lowering efficacy and safety of travoprost $0.004 \%$ and tafluprost $0.0015 \%$ in patients with primary open-angle glaucoma or ocular hypertension.

\section{Methods}

This was a randomized, double-masked, active-controlled, crossover design in which patients were randomized to either travoprost or tafluprost monotherapy administered once daily in the evening for six weeks and were then crossed over to the alternative treatment for another six weeks. The protocol was approved by all relevant institutional review boards and the study was performed in compliance with the ethical principles of the Declaration of Helsinki and Good Clinical Practice. All participating patients provided written informed consent.

\section{Patients}

Eligible patients were at least 21 years old with a clinical diagnosis of primary open-angle glaucoma or ocular hypertension in at least one eye. Patients on IOP-lowering therapy at screening must have required a change in therapy, in the investigator's opinion, to improve efficacy, tolerability, or compliance. They also had to have an IOP $>21 \mathrm{mmHg}$ in at least one eye at $8 \mathrm{am}, \geq 19 \mathrm{mmHg}$ in the same eye at $4 \mathrm{pm}$, and $<35 \mathrm{mmHg}$ in both eyes at all diurnal time points at the baseline visit. In addition, IOPs in both eyes had to be considered safe by the investigator to ensure clinical stability of the visual field and optic nerve throughout the study. Patients were required to have a best-corrected Snellen visual acuity (BCVA) of at least 20/200 in both eyes.

Patients were excluded if they met any of the following criteria: the presence of extreme narrow angle with complete or partial closure in either eye, except for occludable angles treated with a patent iridectomy; any abnormality preventing reliable applanation tonometry in qualifying eye(s); any opacity or patient uncooperativeness that would restrict adequate examination of the ocular fundus or anterior chamber of either eye; concurrent infectious/noninfectious conjunctivitis, keratitis, or uveitis in either eye; intraocular conventional surgery or laser surgery in qualifying eye(s) within three months prior to screening; the risk of visual field or visual acuity worsening as a consequence of participation in the trial, in the investigator's opinion; progressive retinal or optic nerve disease from any cause other than glaucoma; women who were pregnant, lactating, or of childbearing potential and not using reliable means of birth control; any clinically significant, serious, or severe medical or psychiatric condition; any condition that, in the investigator's opinion, would interfere with optimal participation in the study or present a special risk to the patient; participation in any other investigational study within 30 days prior to baseline visit; known history of allergy or sensitivity to any components of the study medications that was deemed to be clinically significant, in the investigator's opinion; use of systemic medications known to affect IOP that have not been on a stable course for seven days prior to the baseline visit or an anticipated change in the dosage during the course of the study; an unwillingness to accept the risk of iris, skin, or eyelash changes associated with prostaglandin therapy; a history or risk of uveitis or cystoid macular edema; a history of ocular herpes simplex; and anticipated use of systemic corticosteroids, by any route except inhaled, for more than two weeks during the trial.

\section{Study design}

Patients who were eligible for trial participation after screening began to wash out their current IOP-lowering medications for the following durations: six weeks for 
prostaglandin analogs and beta-adrenergic blockers, five weeks for alpha-adrenergic blockers, four weeks for epinephrine-related medications, and two days for pilocarpine or carbonic anhydrase inhibitors. At the baseline visit, patients underwent IOP measurements using Goldmann applanation tonometry every two hours, beginning at 8 am and ending at $8 \mathrm{pm}$ (prior to dosing), in order to create an IOP diurnal curve. In addition, at the 8 am baseline visit, patients completed a symptom survey and underwent bilateral BCVA and hyperemia assessments, bilateral slit-lamp biomicroscopy, and urine pregnancy testing (for women of childbearing potential). The symptom survey queried patients on the following symptoms using a scale of 0 to 4 : light sensitivity, blurred/dim vision, stinging/burning, foreign body sensation, pain, and hyperemia. It also included a question about the tolerability of the study medications using a scale of 0 (complete comfort) to 7 (worst pain imaginable) that was not administered at the baseline visit.

Patients who remained eligible for participation after the baseline examination were randomized to receive either travoprost ophthalmic solution $0.004 \%$ or tafluprost $0.0015 \%$ for the first six weeks, after which the first study medication was discontinued and the other study medication was initiated and continued for another six weeks. Patients were instructed on how to use their study medication, ie, one drop in study eye(s) daily at $8 \mathrm{pm}$. Measures conducted at the week 6 and week 12 visits included a solicited symptom survey, bilateral IOP diurnal curve, bilateral BCVA, hyperemia assessment, and bilateral slit-lamp biomicroscopy. Adverse events were collected, monitored, and evaluated throughout the study.

\section{Statistics}

The primary efficacy variable was mean IOP at $8 \mathrm{pm}$, and was measured by a repeated-measures analysis using a matchedpairs platform. Assuming a standard deviation of $2.8 \mathrm{mmHg}$ and an enrollment of 40 patients, this study was designed to provide an $80 \%$ power to detect a $1.25 \mathrm{mmHg}$ difference between therapies. Secondary efficacy variables were also evaluated by repeated-measures analysis. Individual time points were analyzed using a paired $t$-test within the repeatedmeasures analysis. A modified Bonferroni correction $(\alpha / 3)$ adjusted the level to declare significance for individual time points analyses. Other variables, including solicited symptom survey questions, hyperemia, and visual acuity, were analyzed by a paired $t$-test. An appropriate modified Bonferroni correction $(\alpha / 5)$ adjusted the $P$ value to declare significance on the symptom survey. Adverse events were evaluated by a
McNemar test. The data were analyzed by PRN Pharmaceutical Research Network, LLC (Dallas, TX).

\section{Results}

Fifty-one patients were randomized. Forty-eight patients with 92 qualifying eyes completed the study and were included in the intent-to-treat population. Table 1 shows that patients had a mean age of 68.8 years and $60.8 \%$ were female.

As presented in Table 2, the 12-hour mean diurnal IOP was significantly lower with travoprost than with tafluprost (16.9 $\mathrm{mmHg}$ versus $17.5 \mathrm{mmHg} ; P=0.01$ ); a significantly lower IOP was also reported for travoprost at five of the seven individual time points $(P<0.05)$, including at $8 \mathrm{pm}$ $(P=0.01)$, which was the primary endpoint of the study. Both therapies produced a similar pattern of IOP control, with peak IOP reductions observed at the first time point, 12 hours after dosing, and trough reductions noted at $4 \mathrm{pm}$, 20 hours after dosing (Figure 1).

Neither therapy produced a significant increase from baseline in any of the individual symptom scores (light sensitivity, blurred/dim vision, stinging/burning, foreign body sensation, or pain), except for hyperemia, which was increased with both therapies ( $P \leq 0.01$, Table 3 ). Investigator-observed hyperemia was also significantly increased from baseline for both travoprost $(0.26 \pm 0.56, P<0.01)$ and tafluprost $(0.42 \pm 0.54, P<0.01)$, although the increase with travoprost therapy was significantly smaller than with tafluprost $(P<0.01)$. Aside from hyperemia, conjunctival edema, corneal clarity, lens clarity, and lid erythema, no changes from baseline were observed in most measures assessed with slit-lamp biomicroscopy. Visual acuity was not significantly changed with either travoprost $(0.01 \pm 0.02)$ or tafluprost $(0.00 \pm 0.02)$ treatment $(P=0.49)$. No significant difference was noted in patient-reported tolerability between travoprost $(0.90 \pm 0.31)$ and tafluprost $(0.96 \pm 0.20)$ therapies $(P=0.18)$. One patient experienced a mild headache believed not to be treatment-related while on tafluprost therapy, but no other adverse events were reported.

Table I Patient demographics of the safety population

\begin{tabular}{ll}
\hline Demographic & $\begin{array}{c}\text { Total } \\
\mathbf{N}=\mathbf{5} \text { I }\end{array}$ \\
\hline Gender (\%) & \\
$\quad$ Male & 39.2 \\
$\quad$ Female & 60.8 \\
Age (mean \pm SD, years) & $68.8 \pm 9.0$ \\
Race (\%) & \\
$\quad$ Caucasian & 100 \\
\hline
\end{tabular}

Abbreviation: SD, standard deviation. 
Table 2 Mean intraocular pressure at baseline and after six weeks of therapy with travoprost and tafluprost (intent-to-treat population, $\mathrm{N}=48$ )

\begin{tabular}{lllll}
\hline Hour & $\begin{array}{l}\text { Baseline IOP } \\
\text { (mean } \pm \text { SD) }\end{array}$ & $\begin{array}{l}\text { Travoprost IOP Tafluprost } \\
\text { (mean } \pm \text { SD) }\end{array}$ & $\begin{array}{l}\text { P value } \\
\text { IOP } \\
\text { (mean } \pm \text { SD) }\end{array}$ \\
\hline 8 AM & $25.9 \pm 2.45$ & $17.0 \pm 2.36$ & $17.5 \pm 2.20$ & 0.06 \\
I0 AM & $25.0 \pm 3.08$ & $16.7 \pm 2.39$ & $17.3 \pm 2.50$ & $\mathbf{0 . 0 2}^{\mathrm{a}}$ \\
I2 PM & $24.3 \pm 3.47$ & $16.7 \pm 2.47$ & $17.2 \pm 2.46$ & $\mathbf{0 . 0 I}^{\mathrm{a}}$ \\
2 PM & $23.9 \pm 3.22$ & $16.9 \pm 2.69$ & $17.3 \pm 2.77$ & 0.09 \\
4 PM & $24.1 \pm 3.06$ & $17.1 \pm 2.85$ & $17.6 \pm 2.80$ & $\mathbf{0 . 0 I}^{\mathrm{a}}$ \\
6 PM & $24.1 \pm 2.90$ & $16.9 \pm 3.12$ & $17.6 \pm 3.13$ & $<\mathbf{0 . 0 I}^{\mathrm{a}}$ \\
8 PM & $24.3 \pm 3.35$ & $17.1 \pm 3.17$ & $17.7 \pm 3.23$ & $\mathbf{0 . 0 I}^{\mathrm{a}}$ \\
I2-hour mean 24.5 \pm 2.89 & $16.9 \pm 2.59$ & $17.5 \pm 2.62$ & $\mathbf{0 . 0 I}^{\mathrm{a}}$ \\
\hline
\end{tabular}

Note: ${ }^{a}$ Bolded $P$ values represent statistical significance.

Abbreviations: IOP, intraocular pressure; SD, standard deviation.

\section{Discussion}

This is the first published clinical trial that has compared treatment with travoprost $0.004 \%$ with that of tafluprost $0.0015 \%$. In this crossover study of patients with primary open-angle glaucoma or ocular hypertension, both travoprost and tafluprost demonstrated excellent IOP control, showing a mean $7.6 \mathrm{mmHg}$ IOP reduction for travoprost and a mean $7.1 \mathrm{mmHg}$ IOP reduction from baseline for tafluprost. However, travoprost not only produced a significantly lower 12-hour mean IOP but also exhibited significant reductions at five of the seven individual time points, with the two nonsignificant time points demonstrating trends toward statistical significance. These data suggest that travoprost provides a modest but significant advantage in IOP control over tafluprost. Of note is the fact that, similar to previous studies comparing travoprost and latanoprost, ${ }^{11,12}$ travoprost in this study produced superior IOP control in the late afternoon (ie, at $4 \mathrm{pm}$ and $6 \mathrm{pm}$ ). The difference between this study and the previous latanoprost studies is that the significantly greater hypotensive effect demonstrated by travoprost was not restricted to those time points; rather, it was exhibited at all but two of the diurnal time points.

No unexpected safety concerns with either travoprost or tafluprost monotherapy were observed during the course of this clinical trial. Hyperemia is a class effect of prostaglandin analogs, ${ }^{14}$ and both travoprost and tafluprost induced similarly modest levels of hyperemia. Ocular side effects common to topical ophthalmic medications, including light sensitivity, pain, and foreign body sensation, were minimally reported by patients, with mean scores of all side effects surveyed $<0.3$ on a scale of 0 to 4 . Moreover, no differences in patient-reported tolerability were noted, suggesting that travoprost and tafluprost have similar safety and tolerability profiles in this patient population.

This clinical trial with its crossover design and washout period for previous IOP-lowering medications was well controlled, but it did have some limitations. It was designed to provide only six weeks of treatment with each study medication, which makes it challenging to identify any long-term efficacy

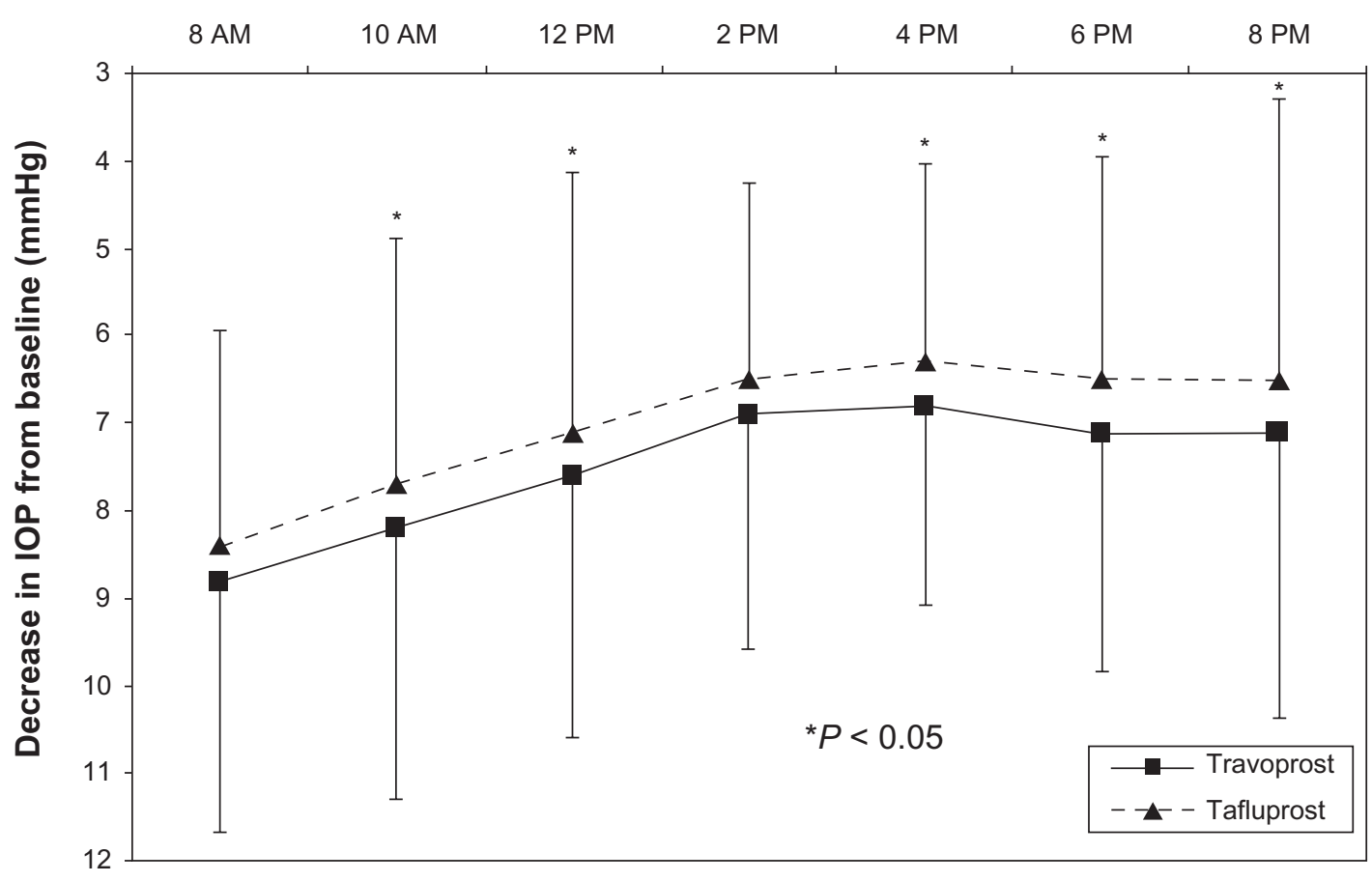

Figure I Decrease in diurnal IOP from baseline produced by travoprost and tafluprost. (intent-to-treat population, $N=48$ ).

Note: *Travoprost showed a significantly larger decrease in IOP from baseline than tafluprost $(P<0.05)$.

Abbreviation: IOP, intraocular pressure. 
Table 3 Mean change from baseline on the symptom survey scores (based on a scale of $0-4$ ) after six weeks of therapy with travoprost and tafluprost (intent-to-treat population, $\mathrm{N}=48$ )

\begin{tabular}{|c|c|c|c|c|}
\hline Question & $\begin{array}{l}\text { Travoprost } \\
\text { (mean } \pm \text { SD) }\end{array}$ & $P$ value & $\begin{array}{l}\text { Tafluprost } \\
\text { (mean } \pm \text { SD) }\end{array}$ & $P$ value \\
\hline Do you experience pain in or around your eyes when exposed to light? & $0.02 \pm 0.25$ & 0.57 & $0.06 \pm 0.24$ & 0.08 \\
\hline Do you experience blurred or dim vision? & $-0.02 \pm 0.33$ & 0.66 & $-0.02 \pm 0.33$ & 0.66 \\
\hline Do you experience stinging or burning? & $0.02 \pm 0.44$ & 0.74 & $0.04 \pm 0.50$ & 0.57 \\
\hline Do you feel that something is in your eyes or under your lids? & $0.04 \pm 0.29$ & 0.32 & $0.06 \pm 0.24$ & 0.08 \\
\hline Do you experience deep pain in or around your eyes? & $0.00 \pm 0.21$ & 1.00 & $0.00 \pm 0.21$ & 1.00 \\
\hline Have you noticed redness in your eyes? & $0.17 \pm 0.21$ & $0.0 \mathrm{I}^{\mathrm{a}}$ & $0.27 \pm 0.49$ & $<0.0 \mathbf{I}^{\mathrm{a}}$ \\
\hline
\end{tabular}

Note: ${ }^{B}$ Bolded $P$ values represent statistical significance.

Abbreviation: SD, standard deviation.

and safety differences between travoprost and tafluprost. Also, although the differences in mean IOP between travoprost and tafluprost were statistically significant, they were small (0.4-0.7 $\mathrm{mmHg})$. Although the clinical significance of the superior IOP control by travoprost is unclear, Konstas et al have demonstrated that small differences in IOP (in $1 \mathrm{mmHg}$ increments) can have a substantial impact on the likelihood of glaucoma progression within certain IOP ranges. ${ }^{15}$

\section{Conclusion}

Travoprost $0.004 \%$ monotherapy administered once daily in the evening produced superior IOP control throughout a 12-hour period compared with tafluprost $0.0015 \%$ in patients with primary open-angle glaucoma or ocular hypertension. Travoprost and tafluprost exhibited similar safety and tolerability profiles.

\section{Acknowledgment}

Medical writing assistance was provided by Jennifer Klem $\mathrm{PhD}$ and funded by Alcon Laboratories, Inc.

\section{Disclosure}

The authors report no conflicts of interest in this work.

\section{References}

1. Vogel R, Crick RP, Newson RB, Shipley M, Blackmore H, Bulpitt CJ. Association between intraocular pressure and loss of visual field in chronic simple glaucoma. Br J Ophthalmol. 1990;74(1): 3-6.

2. Teus MA, Castejón MA, Calvo MA, Pérez-Salaíces P, Marcos A. Intraocular pressure as a risk factor for visual field loss in pseudoexfoliative and in primary open-angle glaucoma. Ophthalmology. 1998; 105(12):2225-2229.

Clinical Ophthalmology

\section{Publish your work in this journal}

Clinical Ophthalmology is an international, peer-reviewed journal covering all subspecialties within ophthalmology. Key topics include: Optometry; Visual science; Pharmacology and drug therapy in eye diseases; Basic Sciences; Primary and Secondary eye care; Patient Safety and Quality of Care Improvements. This journal is indexed on Submit your manuscript here: http://www.dovepress.com/clinical-ophthalmology-journal
3. Terminology and guidelines for glaucoma, IIIrd ed, 2008. European Glaucoma Society Web site. Available at: http://www.eugs.org/eng/ EGS_guidelines.asp. Accessed 2010 Jul 27.

4. Sommer A, Tielsch JM, Katz J, et al. Relationship between intraocular pressure and primary open-angle glaucoma among white and black Americans. The Baltimore Eye Survey. Arch Ophthalmol. 1991; 109(8):1090-1095.

5. Mao LK, Stewart WC, Shields MB. Correlation between intraocular pressure control and progressive glaucomatous damage in primary open-angle glaucoma. Am J Ophthalmol. 1991;111(1):51-55.

6. Heijl A, Leske MC, Bengtsson B, Hyman L, Bengtsson B, Hussein M. Reduction of intraocular pressure and glaucoma progression: Results from the Early Manifest Glaucoma Trial. Arch Ophthalmol. 2002;120(10): 1268-1279.

7. Holmstrom S, Buchholz P, Walt J, Wickstrøm J, Aagren M. Analytic review of bimatoprost, latanoprost and travoprost in primary open-angle glaucoma. Curr Med Res Opin. 2005;21(11):1875-1883.

8. Travatan ${ }^{\circledR}$ [Package insert]. Fort Worth, TX: Alcon Laboratories, Inc.; 2004.

9. Sultan MB, Mansberger SL, Lee PP. Understanding the importance of IOP variables in glaucoma: A systematic review. Surv Ophthalmol. 2009;54(6):643-662.

10. Asrani S, Zeimer R, Wilensky J, Gieser D, Vitale S, Lindenmuth K. Large diurnal fluctuations in intraocular pressure are an independent risk factor in patients with glaucoma. J Glaucoma. 2000;9(2):134-142.

11. Netland PA, Landry T, Sullivan EK, et al; Travoprost Study Group. Travoprost compared with latanoprost and timolol in patients with open-angle glaucoma or ocular hypertension. Am J Ophthalmol. 2001; 132(4):472-484.

12. Konstas AG, Kozobolis VP, Katsimpris IE, et al. Efficacy and safety of latanoprost versus travoprost in exfoliative glaucoma patients. Ophthalmology. 2007;114(4):653-657.

13. Uusitalo H, Pillunat LE, Ropo A; Phase III Study Investigators. Efficacy and safety of tafluprost $0.0015 \%$ versus latanoprost $0.005 \%$ eye drops in open-angle glaucoma and ocular hypertension: 24-month results of a randomized, double-masked phase III study. Acta Ophthalmol. 2010;88(1):12-19.

14. Holló G. The side effects of the prostaglandin analogues. Expert Opin Drug Saf. 2007;6(1):45-52.

15. Konstas AG, Hollo G, Astakhov YS, et al. Factors associated with longterm progression or stability in exfoliation glaucoma. Arch Ophthalmol. 2004;122(1):29-33.

\section{Dovepress}

PubMed Central and CAS, and is the official journal of The Society of Clinical Ophthalmology (SCO). The manuscript management system is completely online and includes a very quick and fair peer-review system, which is all easy to use. Visit http://www.dovepress.com/ testimonials.php to read real quotes from published authors. 